\title{
A novel triple-anchoring technique for hybrid endoscopic mucosal resection
}
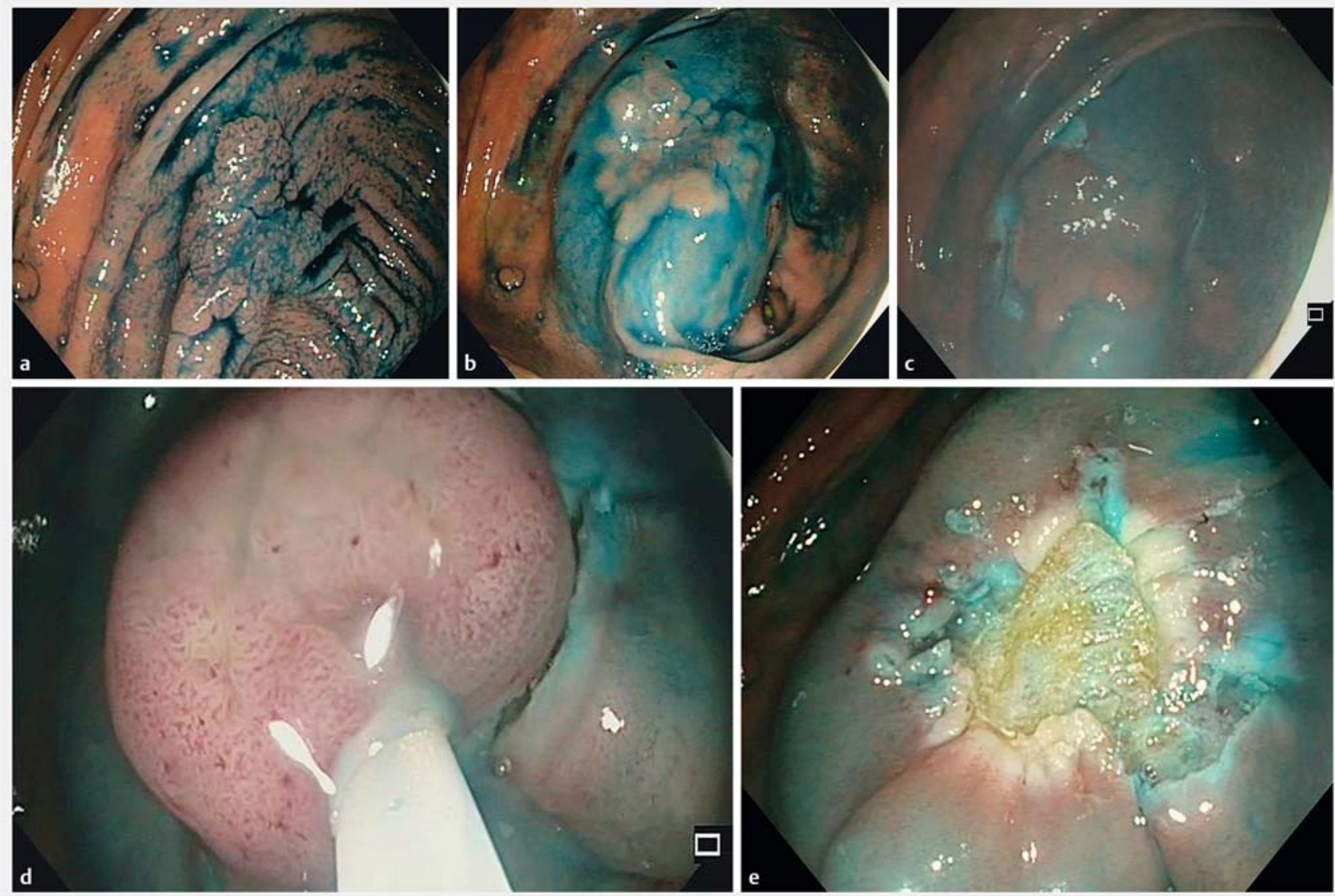

Fig. 1 Endoscopic images showing: a a large flat colonic polyp in the cecum suitable for endoscopic mucosal resection by the triple-anchoring technique; $\mathbf{b}$ the polyp after submucosal injection; c small incisions on the top and on the lateral margins of the lesion, which were made using the tip of the snare in Endocut mode; $\mathbf{d}$ the $25-\mathrm{mm}$ snare grasping the lesion with the triple-anchoring technique; $\mathbf{e}$ the resected area following en bloc capture of the entire large polyp, consistent with macroscopic complete resection.

Superficial colorectal lesions smaller than $20 \mathrm{~mm}$ in size can be safely removed en bloc by endoscopic mucosal resection (EMR). Bigger lesions ( $\geq 20 \mathrm{~mm}$ ) usually require piecemeal EMR, which is associated with a lower curative rate [1] and a higher risk of recurrence [2]. Endoscopic submucosal dissection (ESD) was developed to allow en bloc resection of early stage gastrointestinal lesions. ESD is a technically difficult procedure, which requires specialized training, a longer procedure time, and is associated with a higher risk of perforation compared with $\operatorname{EMR}[3,4]$.

ESD and EMR are not mutually exclusive and a hybrid technique may be a reasonable compromise that makes EMR more reliable by enabling the resection of larger polyp specimens, obtaining clear lateral margins, and reducing procedure times [5]. Here we report a new hybrid EMR technique that is aimed at facilitating mucosal resection of colonic and rectal lesions between $20 \mathrm{~mm}$ and $30 \mathrm{~mm}$ in size.
After the submucosal injection has been performed, small incisions are made on the top and on the lateral margins of the lesion using the tip of the snare $(25-\mathrm{mm}$ SnareMaster; Olympus, Tokyo, Japan), which must be protruding $2 \mathrm{~mm}$ out of the catheter. The small incision on the top of the lesion allows the snare to be anchored as it is opened, while the lateral incisions allow the lesion to be grasped as the snare is being closed, thereby avoiding slippage during the resection ( Fig. 1; Video 1). Before cutting is 


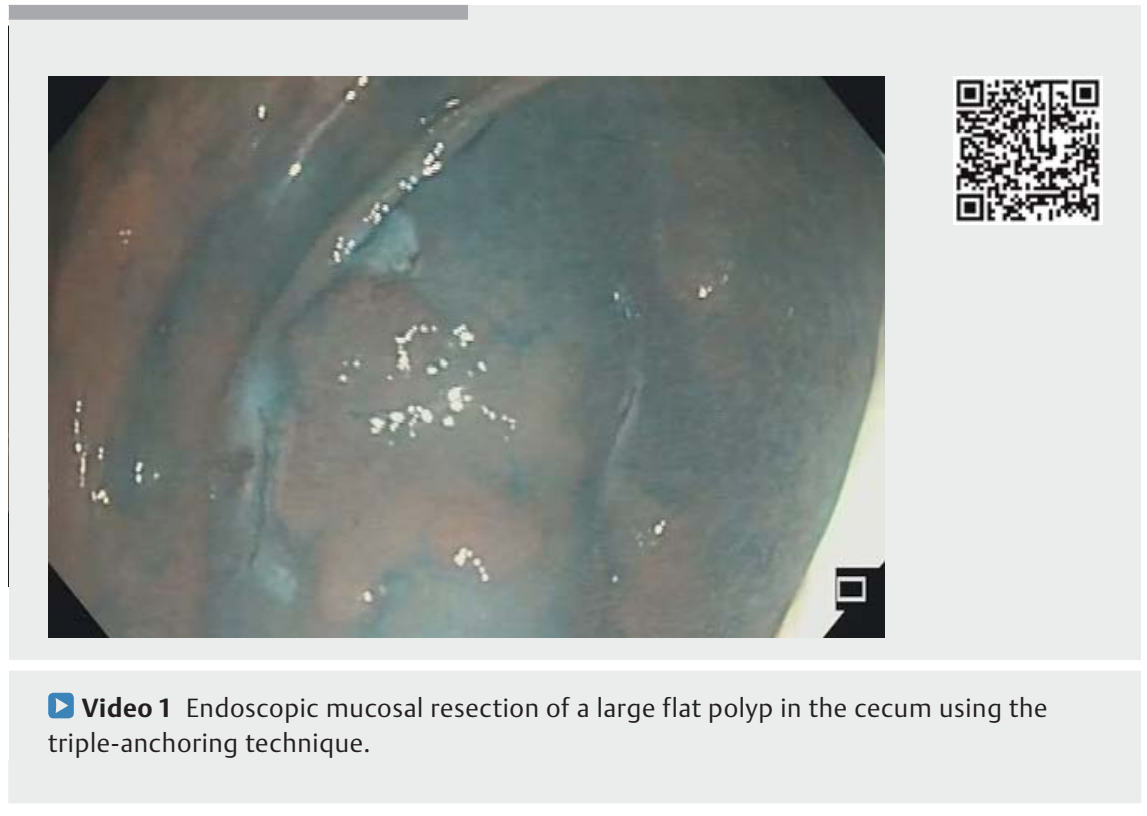

carried out, the lumen is inflated so as to avoid injuries to the muscular layer. At the end of the resection, clips are placed to reduce the risk of complications.

Pathological analysis in the case shown revealed a $20 \times 21-\mathrm{mm}$ low grade tubular adenoma with clear margins ( $\mathrm{R} 0$ resection).

This hybrid technique might be routinely indicated for borderline and/or very flat lesions. Studies are needed in order to understand the safety of the procedure and the risks of residue and/or recurrence.

Endoscopy_UCTN_Code_TTT_1AQ_2AD

\section{Competing interests}

None
The authors

Jun Hamanaka ${ }^{1,2,3}$, Cristiano Spada ${ }^{1}$, Maria Chiara Campanale ${ }^{1}$, Vincenzo Bove ${ }^{1}$, Shin Maeda $^{3}$, Guido Costamagna ${ }^{1}$

1 Digestive Endoscopy Unit, "A. Gemelli" University Hospital, Rome, Italy

2 Department of Gastroenterology, Yokohama Minami Kyosai Hospital, Yokohama, Japan

3 Department of Gastroenterology, Yokohama City University Graduate school of Medicine, Yokohama, Japan

\section{Corresponding author}

\section{Jun Hamanaka, MD}

Largo A. Gemelli 8, 00168 Roma, Italy Fax: +39-06-30157220

J_hamanaka@hotmail.com

[1] Saito Y, Fukuzawa M, Matsuda T et al. Clinical outcome of endoscopic submucosal dissection versus endoscopic mucosal resection of large colorectal tumors as determined by curative resection. Surg Endosc 2010; 24: 343-352

[2] Briedigkeit A, Sultanie O, Sido B et al. Endoscopic mucosal resection of colorectal adenomas $>20 \mathrm{~mm}$ : Risk factors for recurrence. World J Gastrointest Endosc 2016; 8: 276 281

[3] Yahagi N, Fujishiro M, Omata M. Endoscopic submucosal dissection of colorectal lesion. Dig Endosc 2004; 16: S178 - S181

[4] Saito Y, Uraoka T, Yamaguchi Y et al. A prospective, multicenter study of 1111 colorectal endoscopic submucosal dissections (with video). Gastrointest Endosc 2010; 72 : $1217-1225$

[5] Toyonaga T, Man-I M, Morita Y et al. Endoscopic submucosal dissection (ESD) versus simplified/hybrid ESD. Gastrointest Endosc Clin N Am 2014; 24: 191 - 199

\section{Bibliography}

DOI https://doi.org/10.1055/s-0043-121134

Published online: 23.11.2017

Endoscopy 2018; 50: E48-E49

(c) Georg Thieme Verlag KG

Stuttgart · New York

ISSN 0013-726X

\section{ENDOSCOPY E-VIDEOS}

https://eref.thieme.de/e-videos

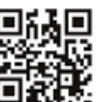

Endoscopy E-Videos is a free access online section, reporting on interesting cases and new techniques in gastroenterological endoscopy. All papers include a high quality video and all contributions are freely accessible online.

This section has its own submission website at

https://mc.manuscriptcentral.com/e-videos 